\title{
Палатопластика с имплантация на хрущяли от носа в мекото небце - метод за лечение на разстройства на дишането по време на сън
}

\author{
Св. Василева', Р. Бенчев² \\ 'МИ - МВР - София \\ ${ }^{2}$, ХИЛ КЛИНИК“АД - София
}

\section{Резюме:}

Целта на настоящия доклад е да представим разработения от нас метод „Палатопластика с имплантация на хрущяли от носа в мекото небце" и да споделим опита си с използването на тази оперативна техника при лечението на пациенти с разстройства на дишането по време на сън. Техниката е базирана на метода Pillar ${ }^{\circledR}$ Palatal Implant System. През 2008 год. възникна идеята при пациенти с комбинирана обструкция на ниво нос (изкривяване на носната преграда със или без хипертрофия на долните носни конхи) и мезофаринкс (в частност обструкция следствие от хипотония на мекото небце или наличие на скрит палатосхизис) едноетапно с извършването на септопластика да вграждаме хрущяли от носа в мускулите на мекото небце. В настоящата публикация представяме критериите за подбор на пациенти, подходящи за осъществяването на този тип хирургична намеса, етапите на осъществяване на оперативната техника и постигнатите от нас резултати от прилагането ѝ при пациенти с хабитуално хъркане, лека и умерена по тежест обструктивна сънна апнея (OSA). Считаме, че предлаганият от нас метод е полезен и ефективен, като успехът е в правопропорционална зависимост от правилния подбор на пациенти.

\section{Summary:}

The goal of this report is to present the developed by us surgical method called „, Palatoplasty with implantation of cartilage from the nose in the soft palate" and to share our experience with the use of this operative technique for the treatment of patients with Sleep Disordered Breathing. The technique is based on the method Pillar ${ }^{\circledR}$ Palatal Implant System. In 2008 arose the idea in patients with combined obstruction of levels: nose (deviated nasal septum with or without hypertrophy of the lower nasal conchas ) and oropharynx (in particular due to obstruction of hypotension of the soft palate or the presence of hidden palatoshizis ), to do Septoplasty in one step with embed cartilages from the nose in the muscles of the soft palate. In this paper we present criteria for selection of patients suitable for the implementation of this type of surgery, steps of completion of surgery and achieved by us results of its application in patients with habitual snoring, mild and moderate Obstructive sleep apnea (OSA). We believe that our proposed method is useful and effective, and success rate is dependent on precise patients selection.
$\mathrm{P}$ азстройствата на дишането по време на сън (SDB) са проблем, който набира все по-голяма популярност през последните години във връзка с широкото си разпространение и значимите негативни последици върху здравето на хора в млада и трудоспособна възраст. Хабитуалното хъркане засяга според най-разпространените статистики между 17, 9\% и 40\% от мъжете и между 7.4\% и 19\% от жсените в средна възраст. Разпространение на OSA е между 4-9\% сред мъжете и между 2-4\% сред жените, като се счита, че $80-90 \%$ от хората с OSA остават недиагностицирани (1, $2,3,4)$. Докладваното разпространение на $\boldsymbol{O S A}$ сред децата е 5-6\% (5).

При пациенти с хабитуално хъркане, синдром на повишено съпротивление в ГДП (UARS) и лека до умерена по степен OSA обструкцията най-често е локализирана в областта на носа и мезофаринкса (често съчетана на тези две анатомични нива). Обструкция на ниво хипофаринкс най-често се наблюдава като елемент от обструкция на няколко нива и е типична за пациенти с тежка по степен OSA.

През 2008 год. възникна идеята при пациенти с комбинирана обструкция на ниво нос и мезофаринкс (в частност обструкция следствие от хипотония на мекото небце или наличие на скрит палатосхизис) да вграждаме хрущяли от носа в мускулите на мекото небце. Нарекохме операцията палатопластика $\boldsymbol{c}$ имплантация на хруцяли. Техниката е базирана на метода Pillar ${ }^{\circledR}$ Palatal Implant System, въведен в клиничната практика през 2003 г. Чрез вграждане на импланти в мекото небце се осъществява неговото 
втвърдяване и релативно скъсяване, което води до намаляване на способността му да вибрира и да колабира към ретропалатиналното пространство. Поставените импланти водят до повишаване твърдостта на небцето както директно (поставен ригиден имплант), така и вследствие образуването на фиброзна капсула около импланта в отговор на възпалителна реакция (6). Една от причините да потьрсим алтернатива на метода Pillar Procedure беше фактьт, че за голяма част от нашите пациенти закупуването на готовата система от 3 импланта, предлагана от фирма Medtronik, беше непосилно като цена. Използването на собствен хрущял се оказа идеална алтернатива и след първата успешна имплантация през 2008 год. започнахме рутинно да прилагаме метода при пациенти, индицирани за този тип намеса. Като самостоятелна терапия методът е удачен за лечение на пациенти със съчетана обструкция на носното дишане с обструкция от меко небце. Това най-често са пациенти с хабитуално хъркане, UARS и лека или умерена по тежест OSA. В съчетание с други методи (тонзилектомия, методи за преодоляване на обструкцията на ниво хипофаринкс) техниката може да се използва и за лечение на пациенти с тежка по степен OSA, като елемент от хирургия на няколко нива.

\section{Материал и методика}

\section{1. Материал}

За период от 5 години (2008 - 2013) септопластика, съчетана с палатопластика с имплантация на хрущяли (като изолирани оперативни намеси - без тонзилектомия, резекции на мекото небце и хипофарингеална хирургия), извършихме при общо 37 пациенти - 31 мъже и 6 жени. Пациентите бяха на възраст от 21 до 58 години.

На база анамнеза, резултати от клиничния преглед и обективни изследвания разделихме пациентите на 3 групи:

Таблица 1. Разпределение на пациентите по вид и тежест на дихателното разстройство по време на сън:

\begin{tabular}{lccc}
\multicolumn{1}{c}{ Групи } & Жени & Мъже & Общо \\
I. Пациенти с хабитуално & 6 & 14 & $20(54 \%)$ \\
$\begin{array}{l}\text { хъркане } \\
\text { II. Пациенти с лека по }\end{array}$ & 1 & 10 & $11(30 \%)$ \\
$\begin{array}{l}\text { тежест OSA } \\
\text { III. Пациенти с умерена по } \\
\text { тежест OSA } \\
\text { Общо: }\end{array}$ & 0 & 6 & $6(16 \%)$ \\
& 7 & 30 & $37(100 \%)$
\end{tabular}

Критериите за разделяне на пациентите по групи разработихме на база най-новата класификация на разстройствата на дишането по време на сън, публикувана през 2005 год. от American Academy of Sleep Medicine (AAMS) (7), а именно:

Наличие на хабитуално хьркане приемахме, когато:

- Om анамнезата: Свидетелство от партньора за силно, обичайно хъркане по време на сън. Липса на сънливост през деня и липса на апноични паузи по време на сън (по данни на партньора).

- Изразеност на симптома „Хъркане“-оценка от партньора по скали честота и интензитет от 1 до 4 (ВАС): 3 или 4

- ESS score: под 10 (липса на повишена сънливост през деня)

Наличие на обструктивна сьнна апнея приемахме, когато:

- Om анамнезата: Свидетелство от партньора за силно, обичайно хъркане по време на сън, наблюдавани от него периоди на спиране на дишането по време на сън. Докладвана от пациента повишена сънливост през деня и наличие на поне 3 от останалите типични за заболяването симптоми.

- Изразеност на симптома „Хъркане“-оценка от партньора по скали честота и интензитет от 1 до 4 ( ВАС): 3 или 4

- ESS score: над 10 (повишена сънливост през деня)

- $\boldsymbol{A H I}$ от 5 до 15 за час сън - лека по тежест SOSA и $\boldsymbol{A H I}$ между 16 и 30 за час сън - умерена по тежест SOSA.

\section{За трите групи:}

- Клиничен преглед - в проучването включихме само пациенти с изолирана обструкиия на нива нос и ретропалатинално пространство - наличие на неадекватно носно дишане (резултат от девиация на носната преграда със или без хипертрофия на долните носни конхи), съчетано с обструкция от меко небце (ретропалатинално ниво) - хипотонично меко небце и/или скрит палатосхизис, изразен колапс на ретропалатинално ниво. Пациенти с обструкция от небни тонзили и на нива епифаринкс, хипофаринкс и ларинкс (TS - 0, I, II; FTP - I-II) не бяха включвани в това проучване. 


\section{2. Методика}

Диагнозата поставяхме на база:

1. Анамнеза - винаги с участието на партньора. Насочено търсехме симптома „силно, обичайно хъркане по време на сън” и разпитвахме за наблюдавани от партньора епизоди на спиране на дишането по време на сън. Търсехме и останалите признаци на сънна апнея (сънливост през деня, никтурия, изпотявания в горната част на тялото по време на сън и т.н) и свързаните с нея коморбидни заболявания - хипертония, преживени сърдечно-съдови инциденти, ендокринни заболявания и т.н.

Партньорът попълваше въпросници (BAC) за оценка честотата и интензитета на хъркане преди и след оперативната намеса.

Таблица 2. ВАС за оценка на честота на хъркане

\begin{tabular}{|c|c|c|c|c|}
\hline \multirow{2}{*}{$\begin{array}{c}\text { Вашият парт- } \\
\text { ньор хърка: }\end{array}$} & $\begin{array}{c}\text { Всяка } \\
\text { вечер }\end{array}$ & $\begin{array}{c}\text { Повече от 4-5 нощи } \\
\text { през седмицата }\end{array}$ & $\begin{array}{c}\text { Понякога (след консумация на алкохол, седатива, } \\
\text { при определена позиция на тялото) }\end{array}$ & Не хърка \\
\cline { 2 - 5 } & 4 т. & 3 т. & 2 т. & 1 т. \\
\hline
\end{tabular}

Таблица 3. ВАС за оценка на интензитета на хъркане

\begin{tabular}{|c|c|c|c|c|}
\hline \multirow{2}{*}{$\begin{array}{c}\text { Хъркането е } \\
\text { със сила: }\end{array}$} & $\begin{array}{c}\text { Чува се и извън стаята, в } \\
\text { която партньорът ми спи }\end{array}$ & $\begin{array}{c}\text { Буди ме по време } \\
\text { на сън }\end{array}$ & $\begin{array}{c}\text { Пречи ми да заспя, но не ме } \\
\text { буди през нощта }\end{array}$ & $\begin{array}{c}\text { Не ми } \\
\text { пречи }\end{array}$ \\
\cline { 2 - 5 } & 4 т. & $3 \mathrm{~T}$. & 2 т. & $1 \mathrm{T.}$ \\
\hline
\end{tabular}

Всички пациенти попълваха и Epworth Sleepiness Scale за субективна оиенка на сънливостта през деня.

\section{Клиничен преглед}

\section{1. Общ статус}

Наред с оценката на рутинно приетите при изследването на общия статус критерии, задължително изчислявахме и стойността на т. нар. BMI (body mass index) по формулата:

\section{BMI = теглото (кг) $\mathbf{x}$ височината (м)}

Съобразявахме се с факта, че при ВMI $>40$ оперативното лечение не е индицирано като първи метод на избор.

\section{2. Локален статус}

Локалният УНГ статус включваше задължително, т. нар. ниво - диагностика: насочено търсене на обструкция на определено ниво. Прецизната оценка е невъзможна без използване на оптични техники - много от нивата са трудно достьпни за оглед със стандартните методи.

\section{1. Изследване на носа и носната проходи- мост}

- Външен оглед на носа

\section{- Предна риноскопия}

- Задължителен елемент от изследването на носа беше ендоскопията на носните ходове.
- На пациентите с анамнестични и клинични данни за проблем с носното дишане представяхме въпросник (ВАС) с молба да оценят дишането си по скала от 1 до 4 за всяка ноздра преди и след поставяне на вазоконстрикторни капки в носа (ориентирахме се дали се касае за динамична или за статична обструкция).

Същата ВАС пациентите, при които бяха извършени оперативни намеси за подобряване на носното дишане, попълваха и при проследяването им в следоперативния период.

- За обективна оценка на носното дишане използвахме акустичната ринометрия.

Не сме извършвали обективно изследване на всички пациенти. Използвахме акустична ринометрия при част от пациентите, където имаше разминаване между субективните оплаквания и морфологичните изменения, установени при прегледа.

От пациентите, включени в настоящото проучване, акустична ринометрия извършихме при 13 пациенти (35\%), от които 9 мъже и 4 жени.

\section{2. Изследване на епифаринкса}

При всички, включени в проучването пациенти, огледът на епифаринкса извършвахме и с флексибилен (по-рядко и с ригиден) ендоскоп. Това беше етап от цялостния ендоскопски оглед, започващ от носа, през епифаринкса, мезофаринкса, хипофаринкса и до ларинкса. 
В настоящото проучване не бяха включени пациенти с обструкция на ниво епифаринкс.

\section{3. Изследване на мезофаринкса}

Мезофаринксът е лесно достъпен за оглед, дори и без използването на специално оборудване. Чрез мезофарингоскопия оценявахме размера и особеностите на небните тонзили, мекото небце и увулата, твърдото небце и езика.

При ендоскопския оглед на мезофаринкса също получавахме важна информация за размера на ретропалатиналното пространство, тонзилите и базата на езика и обструкцията, която те
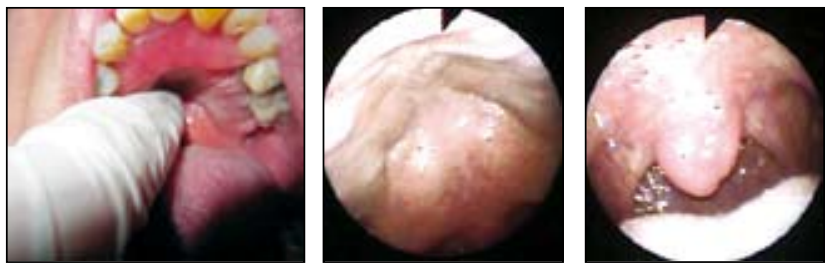

Фиг. 1. Палпация на твърдо небце при пациент със скрит палатосхизис. Липсва увула бифида

създават. Чрез палпация търсехме долния ръб на костната част на твърдото небце. Установихме неочаквано висок процент $(35 \%$ - общо 13 от включените в проучването пациенти), на скрит палатосхизис - по-къса в различна степен костна част на твърдото небце, което клинично се изявяваше със значителен колапс към ретропалатиналното пространство при прегльщане.

В настоящото проучване бяха включени само пациенти, при които обструкцията на ниво мезофаринкс изхождаше от мекото небце и увулата - TS 0-I-II, FTP- I-II, т.е. без наличие на сигнификантна обструкция от небни тонзили и база на езика.

\section{4. Изследване на хипофаринкс и ларинкс}

Хипофаринксът и ларинксът са също области, трудно достъпни за оглед с класическите методи. Индиректната ларингоскопия е добър метод за ориентация (скрининг) при обследване на тези зони, но екзактната оценка изисква фиброоптично изследване. Оценката на обструкцията на тези нива осъществявахме след фиброоптично изследване. В настоящото проучване не включихме пациенти с обструкция на нива хипофаринкс и ларинкс.

\section{5. Помощни методи}

- Muller's maneuver: Лесен за изпълнение метод, които дава полезна информация относно способността за колапс на меките тъкани в двете най-чести нива на обструкция - ретропалатинално и ретроглотично пространство. При всички включени в настоящото проучване пациенти използвахме този прийом. Не включихме в проучването пациенти с колапс на ретроглотично ниво.

\section{6. Обективни методи за изследвания на съня:}

Полиграфия извъриихме при всички пациенти, които съобщиха в анамнезата за повишена сънливост през деня и чиито партньори докладваха наблюдавани епизоди на спиране на дишането по време на сън. Това бяха и пациенти, при кочто сборът от точки по ESS беше равен или по-висок от 10.

Извършихме общо 17 полиграфии предоперативно и 14 след оперативните намеси. ( 11 с полиграф на фирма Pilips - „Stardust TM II Respironics” и 20 записа с полиграф „Sleep Care TM" на фирма BMC)

\section{Оперативно лечение}

Едноетапно със септопластиката при всички включени в това проучване пациенти (37 - 7 жени и 30 мъже) извършвахме и имплантация на хрущяли от носа в мекото небце. При 11 пациенти (8 мъже и 3 жени) извършихме и RF-каутеризация на долни носни конхи.

\section{Палатопластика с имплантация на хрущя- ли от носа - хирургична техника:}

1. Анестезията беше обща, защото операцията винаги се комбинираше със септопластика.

2. При корекцията на носната преграда винаги е възможно да се изреже достатъчно хрущял, за да се оформят 3 лентовидни фрагмента с приблизителна ширина $2-3$ мм и дължина $2-2,5$ см единият и $1,5-2$ см останалите два.

3. Със скалпел правехме хоризонтална инцизия на лигавицата на небцето на нивото на долния ръб на костта по срединната линия (Фиг. 2). 

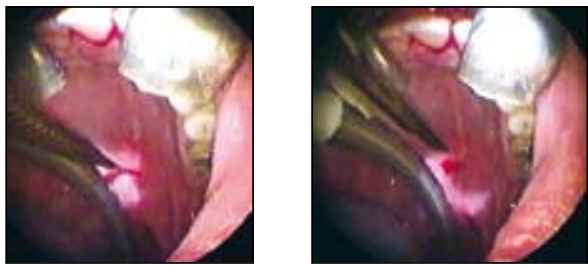

Фиг. 2. Инцизия на лигавицата на небцето по срединната линия на нивото на долния ръб на костта

4. С форцепс по Jacobson или Negus оформяхме тунел в мускулите на мекото небце - кървене почти липсва и формирането на тунела никак не е трудно (Фиг. 3).
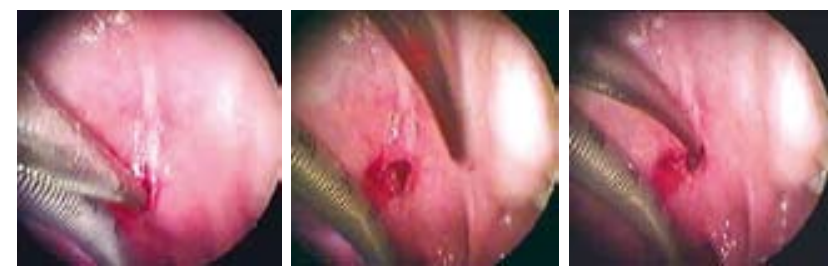

Фиг. 3. Оформяне на тунели в мускулите на мекото небце

5. Поставяхме най-дългия имплант (обикновено единият оставяхме с 2-4 мм по-дъльг) в сформирания мускулен тунел по медиалната линия на небцето - с пръст зад небцето контролирахме поставянето на импланта.

Фиг. 4. Хрущялен имплант
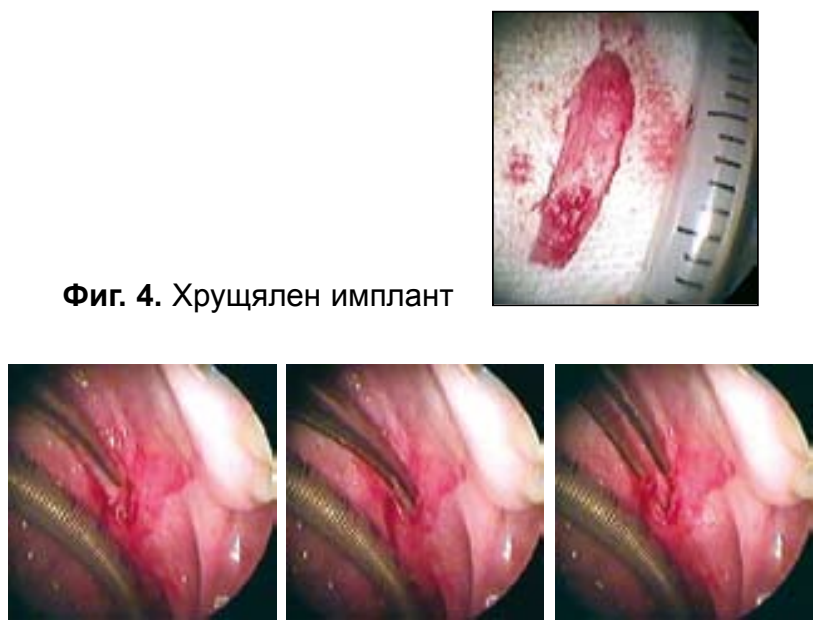

Фиг. 5. Поставяне на импланта във формирания тунел в мускулите на небцето

Долният край на импланта не бива да навлиза в увулата, а да остава няколко милиметра над основата.

По аналогичен начин вграждахме и останалите 2 хрущяла успоредно на първия и на около 2 мм от него парамедианно.
6. Зашивахме инцизията с нерезорбируем конец (3/0 или 4/0).
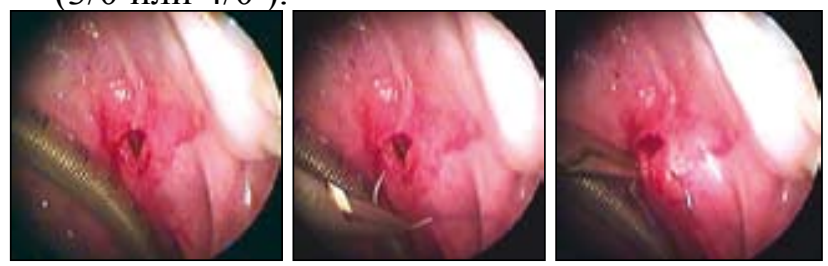

Фиг. 6. Зашиване на инцизионния отвор
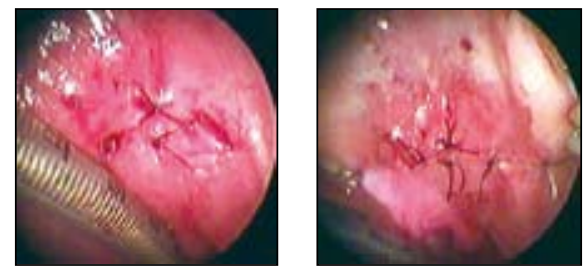

Фиг. 7. След затваряне на инцизиите

\section{Резултати}

От първоначално включените в проучването 37 пациенти за проследяване и контролен преглед между 9 и 13 месец след оперативната намеса се явиха 33 пациенти (89\%). Не се явиха на контролен преглед общо 4 пациенти (мъже - един от групата с хабитуално хъркане, двама с лека по тежест OSA и едни от групата с умерена по тежест OSA). Като успешен приемахме резултата от лечението, когато:

\section{I. За трите групи пациенти:}

- Om анамнезата: Липса на силно, обичайно хъркане по време на сън - свидетелство от партньора.

\section{- Изразеност на симптома „Хъркане”:}

- ВАС честота (от 1 до 4) : 1 или 2

- ВАС интензитет (от 1 до 4) : 1 или 2

- ESS score: под 10 (липса на сънливост през деня)

II. За групите пациенти сьс синдром на обструктивна сънна апнея:

- Лека по степен - $\boldsymbol{A H I}$ под 6 (липса на значима обструкция на дишането по време на сън)

- Умерена по тежест - $\boldsymbol{A H I}$ под 15 (от умерена към лека по степен OSA)

На база заложените критерии отчетената ефективност беше: 


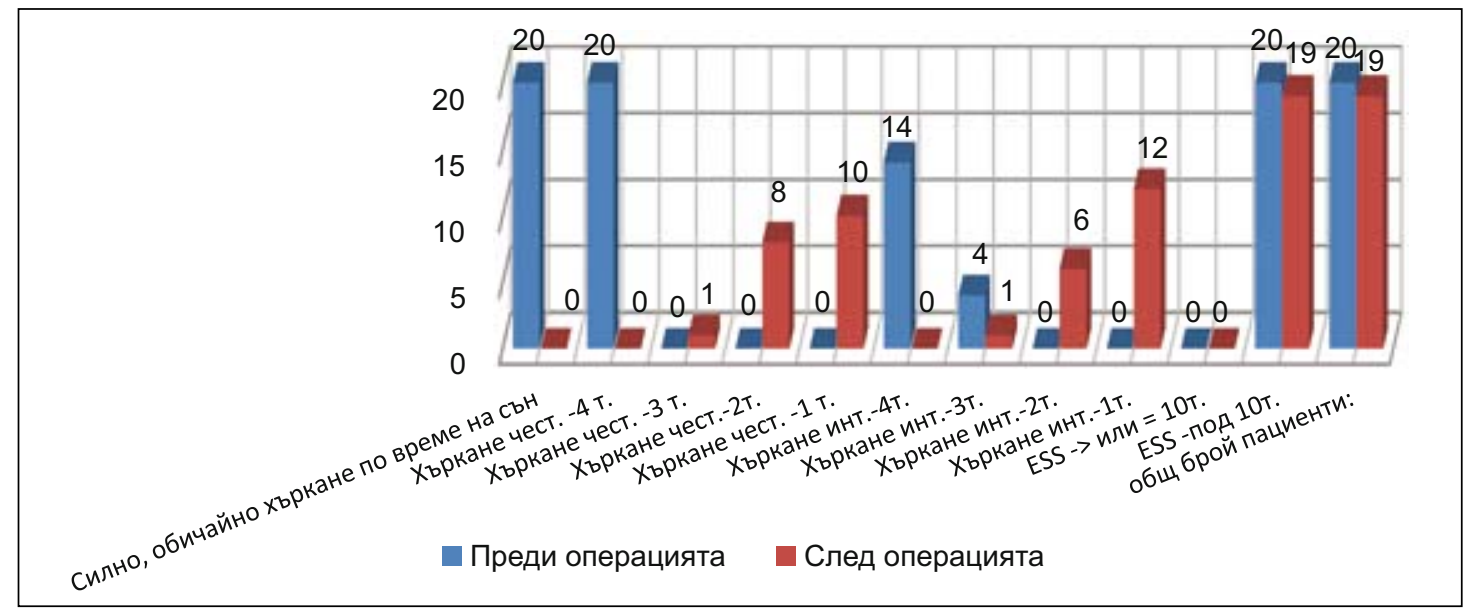

Диаграма 1. Ефективност от оперативното лечение при пациентите с хабитуално хъркане: Ефективност от оперативното лечение при пациентите с хабитуално хъркане

Ефективност по всички поставени критерии за групата 95\%. Неуспех отчетохме при един от мъжете по критерии честота и интензитет на хъркането (по 3 точки).

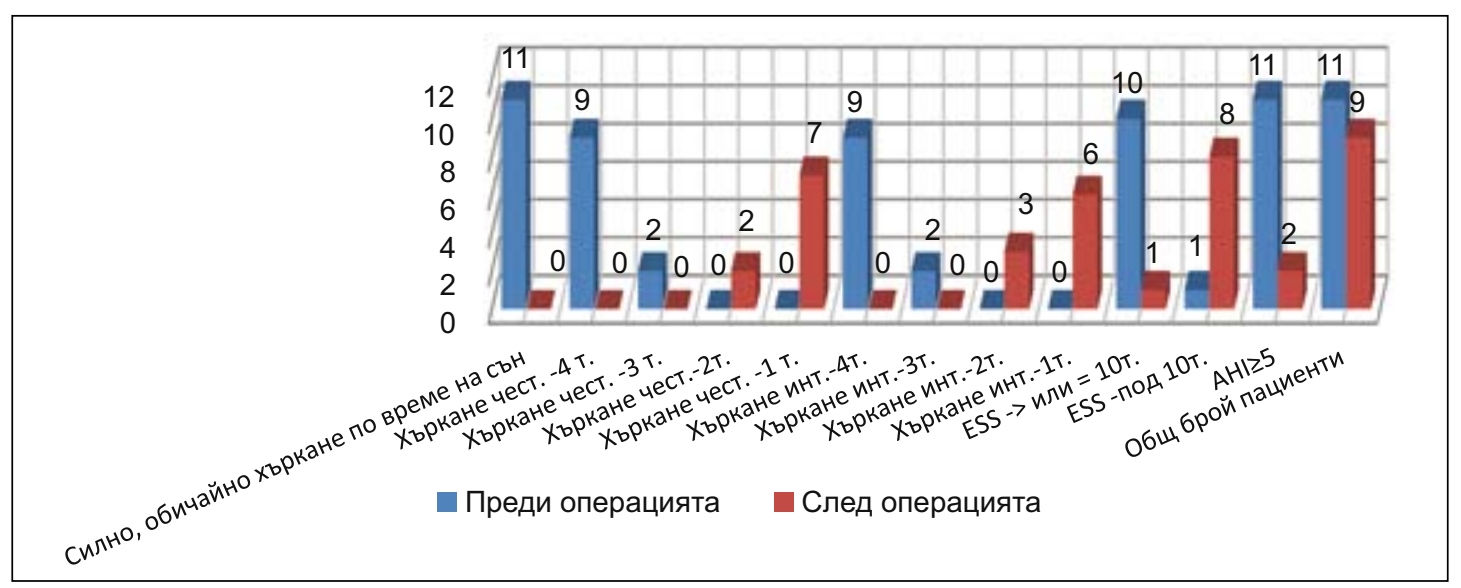

Диаграма 2. Ефективност от оперативното лечение при пациентите с лека по степен OSA

Ефективност по всички поставени критерии за групата 78\%. Неуспех отчетохме при двама от мъжете по критерии: редукция на АНІ - при единия от стойност 14 преди оперативните намеси АНІ след операциите беше 8 , при другия от 13 на 7. При единия от тези пациенти и сборът от точки по ESS беше 11 след операциите (от 13 т. преди намесите).

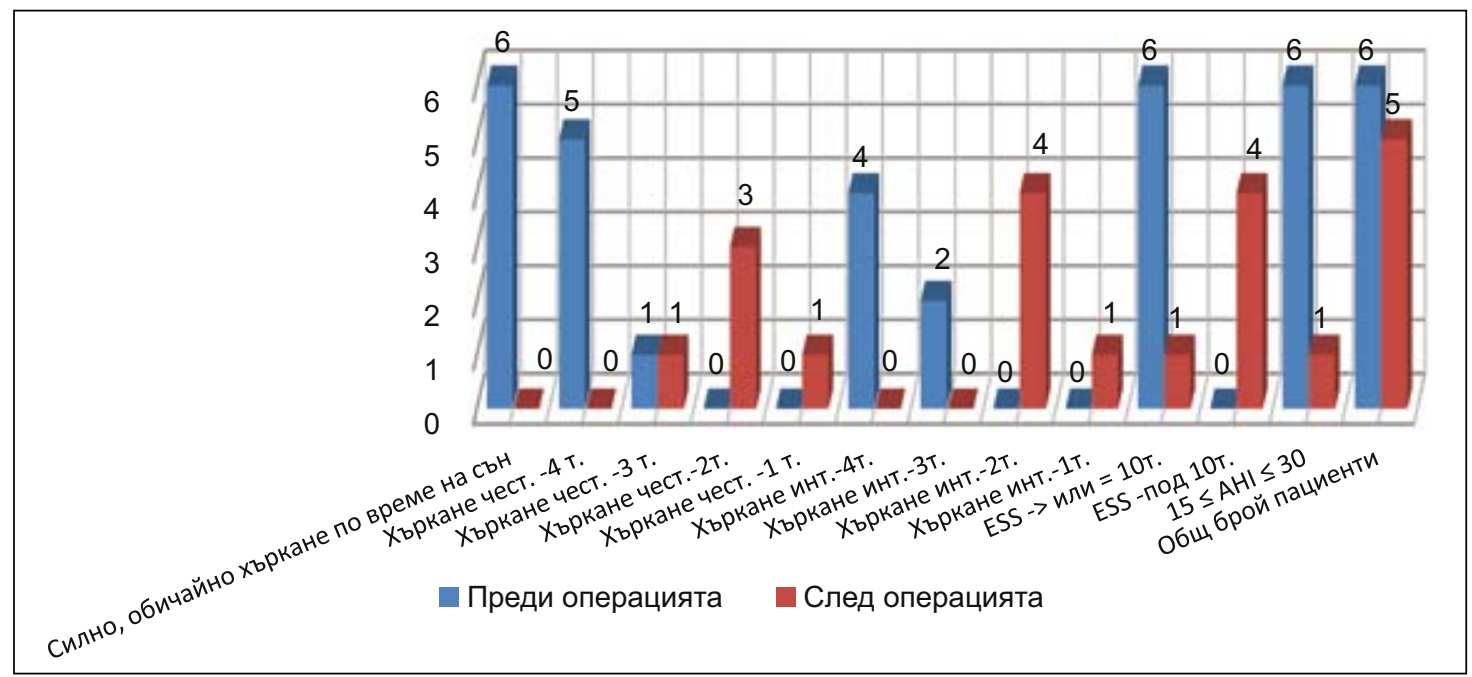

Диаграма 3. Ефективност от оперативното лечение при пациентите с умерена по степен OSA 
Ефективност по всички поставени критерии за групата 80\%. Неуспех отчетохме при един от мъжете по критерии: редукция на АНI - от стойност 21 преди оперативните намеси АНІ след операциите беше 17 и по критерий честота на хъркането - съпругата съобщи, че пациентът хърка повече от 3-4 вечери през седмицата (3 т.), въпреки че интензитетът на хъркане е много понисък - пречи ѝ да заспи, но не я буди по време на сън (2 т.).

Ефективност на оперативните намеси при всички включени в проучването пациенти по зададените критерии 88\% (от 33 явили се на контролен преглед, неуспех отчетохме при 4 пациенти).

По отношение на усложненията: При един от пациентите на първия ден след операцията беше изпуснал конецът, с който затворихме една от инцизиите, и хрущяльт пролабираше през отвора. Затворихме инцизията под местна анестезия. Оток на мекото небце липсваше или беше много слабо изразен - не се е налагало да ползваме кортикостероиди след операцията. Болката също беше слаба - не се е налагало да даваме обезболяващи дори на първия ден след операцията. Не сме имали инфекции, кървене, екструзия на хрущяли и други по-сериозни усложнения след осъществяване на палатопластика с имплантация на хрущяли.

\section{Заключение и изводи}

Настоящото проучване включва сравнително мальк брой пациенти и периодът на просле-

\section{References}

1. Young T, Palta M, Dempsey J, et al. The occurrence of sleepdisordered breathing among middle-aged adults. N Engl J Med 1993; 328(17): 1230-1235

2. Larsson LG, Lindberg A, Franklin KA, et al. Gender differences in symptoms related to sleep apnea in a general population and in relation to referral to sleep clinic. Chest 2003; 124(1): 204-211

3. Enright PL NA, Wahl PW, Manolio TA, et al. Prevalence and correlates of snoring and observed apneas in 5201 older adults. Sleep 1996; 19(7): 531-538

4. Caples SM, Gami AS, Somers VK. Obstructive sleep apnea. Ann Intern Med. Feb 1 2005; 142(3): 187-97 дяване (средно 1 година) вероятно също не е достатъчен, но на база получените от нас резултати считаме, че септопластиката, съчетана с палатопластика с имплантация на хрущяли от носа в мекото небце, е удачен метод за лечение на разстройствата на дишането по време на сън. Успеваемостта е в пропорционална зависимост не толкова от тежестта на разстройството (определена на база полисомнография), колкото от правилния подбор на пациенти - техниката е ефективна при обструкция, локализирана на нива нос и мезофаринкс (в частност меко небце). Най-ефективни са оперативните намеси по отношение на субективната симптоматика - хъркане (анамнеза 100\% ефективност - липса на силно, обичайно хъркане по време на сън докладваха всички партньори след оперативните намеси, въпросници - хъркане честота и интензитет - 94\%) и сънливостта през деня (ESS $<10$ точки - 94\% ефективност). По-трудно е повлияването на обективните показатели - AНI - 79\% ефективност (успех при 11 от проследени 14 пациенти).

Предимства на метода са: технически лесен за изпълнение, евтин - не се налага закупуване на импланти, високоефективен - при правилно поставени индикации средна ефективност 88\% за всички включени в проучването пациенти.

Забележка: Всички снимки в настоящата публикащия са от ендоскопски записи от архива на УНГотделение при МИ - МВР.

5. Guilleminault C, Lee JH, Chan A. Pediatric obstructive sleep apnea syndrome. Arch Pediatr Adolesc Med. Aug 2005; 159(8): 775-85

6. Friedman M, Ramakrishnan V, Bliznikas D, et al. Patient selection and efficacy of Pillar implant technique for treatment of snoring and obstructive sleep apnea/hypopnea syndrome. Otolaryngol. Head Neck Surg. 2006; 134(2): 187-196

7. International Classification of Sleep Disorders: Diagnostic and Coding Manual (ICSD-2) 2005. American Academy of Sleep Medicine. 2005 